\title{
Effective utilization of coal fly ash containing unburned carbon
}

\author{
M. Miyake, V. Kumar Jha, Y. Kimura \& M. Matsuda \\ Department of Material and Energy Science, \\ Graduate School of Environmental Science, Okayama University, \\ Tsushima-Naka, Okayama 700-8530, Japan
}

\begin{abstract}
We investigated the conversion process of coal fly ash with unburned carbon at greater than ca. 6 mass\%, which has fallen behind in terms of resource recovery. As a result, composite materials consisting of zeolite A and/or zeolite $\mathrm{X}$ with good crystallinity and activated carbon were successfully prepared by $\mathrm{NaOH}$ fusion treatment at $750^{\circ} \mathrm{C}$ in $\mathrm{N}_{2}$ flow followed by hydrothermal treatment. The type of zeolite phase formed was dependent on the hydrothermal treatment conditions including $\mathrm{NaOH}$ concentration. The resulting composite materials exhibited removal characteristics for heavy metal ions such as $\mathrm{Ni}^{2+}, \mathrm{Cd}^{2+}$ and $\mathrm{Pb}^{2+}$. In this paper, we describe the conversion of the main $\mathrm{SiO}_{2}-\mathrm{Al}_{2} \mathrm{O}_{3}$ components and unburned carbon in coal fly ash into zeolite-activated carbon composite materials by a chemical process and the removal characteristics of the resulting materials.
\end{abstract}

Keywords: coal fly ash, zeolite, fusion treatment, hydrothermal treatment, removal characteristics.

\section{Introduction}

Fossil fuels are of great importance because they can be burned, producing significant amounts of energy. The burning of fossil fuels produces several billion tones of carbon dioxide per year globally. Therefore, in order to reduce the air pollution, several countries have put forward their environmental regulations. Under the regulations, coal-fired power plants will need to reduce their emissions by more than $50 \%$ within the next decade. Due to the strict regulations on the burning of coal, coal fly ash (CFA) contains variable amounts 
of unburned carbon at less than $c a .20$ mass\%, depending upon the variations in the characteristics of different coal sources and coal-fired boilers. As the presence of such unburned carbon in CFA makes it difficult to use as a raw material for cement manufacturing and construction materials, much of CFA is ultimately dumped in landfills [1].

The reutilization of thus-dumped solid-waste CFA is the need of present context. Besides the utilization of bulk CFA, several potential uses of CFA have been reported as additives for the capture of industrial and water treatment wastes, sources of valuable metals, adsorbents for flue gas desulfurization, fireproofing materials, filter materials for the production of various products, ceramic applications and synthesis of several types of zeolites [2-14].

Owing to rich in $\mathrm{Al}_{2} \mathrm{O}_{3}$ and $\mathrm{SiO}_{2}$ contents of CFA, the synthesis of zeolites by hydrothermal alkaline treatment is a promising technique for its reutilization. In addition to conventional hydrothermal alkaline treatment, there are a number of synthetic approaches to hydrothermal synthesis, such as a two-step method (fusion followed by hydrothermal treatment) [14-16] and the dry or molten-salt method [17]. These alternative methods were developed in order to achieve high synthesis efficiency and/or zeolite content. Furthermore, the presence of unburned carbon in CFA, which is burden for the utilization of bulk CFA, was successfully utilized by the two-step method [14]. Namely, the unburned carbon was converted into activated carbon, and composite materials consisting of zeolite X (Na-X) and/or zolite A (Na-A) and activated carbon were prepared.

In the present study we have investigated the conversion process of unburnedcarbon-contained-CFA into the composite of activated carbon and zeolites. The heavy metal ions removal characteristics of thus obtained composite materials were examined.

\section{Materials and methods}

\subsection{Sample preparation and characterization}

CFA used in this study was obtained from the Chugoku Electric Power Company Limited at Mizushima, Okayama, Japan. The chemical compositions of CFA were analyzed using X-ray fluorescence (XRF; Rigaku ZSX-100s). The average mass $\%$ of unburned carbon was analyzed by thermogravimetry-differential thermal analysis (TG-DTA; Rigaku TAS-100). The phases present in CFA was analyzed by powder X-ray diffractometer with monochromated $\mathrm{CuK} \alpha$ radiation (XRD; Rigaku RINT2100/PC), and its shape and texture were observed using scanning electron microscope (SEM; JEOL JSM-6360FS).

CFA was mixed with $\mathrm{NaOH}$ with varying $\mathrm{CFA} / \mathrm{NaOH}$ mass ratio 1-3 and fired at $750^{\circ} \mathrm{C}$ for $1 \mathrm{~h}$ in a $\mathrm{N}_{2}$ atmosphere. After the $\mathrm{NaOH}$ fusion treatment, the mixture was ground and suspended in various amounts of deionized water (12-48 $\mathrm{ml}$ ) in order to control $\mathrm{NaOH}$ concentration followed by stirring and aging for 2$24 \mathrm{~h}$ at room temperature. The slurry was sealed in a Teflon-lined autoclave and heated at $60-80^{\circ} \mathrm{C}$ for $2-24 \mathrm{~h}$. After hydrothermal treatment, the sample was washed several times using deionized water, dried at $50^{\circ} \mathrm{C}$ overnight, and then collected for characterization. 
The resulting materials were identified by XRD, and their specific surface areas were evaluated by measuring isothermal adsorption of $\mathrm{N}_{2}$ at $77 \mathrm{~K}$ based on the BET method (BEL-Japan BELSORP 18 PLUS). The morphologies of the products were observed by SEM.

\subsection{Uptake of metal ions}

All the metal ion solutions were prepared separately, containing ppm concentrations of analytical grade metal chlorides, which were converted to $\mathrm{mmol} / \mathrm{L}$ for later calculations. The resulting composite materials were subjected to $\mathrm{Ni}^{2+}, \mathrm{Cd}^{2+}$ and $\mathrm{Pb}^{2+}$ removal experiments under the following conditions: temperature $25^{\circ} \mathrm{C}$ (room temperature), solid/solution ratio $100 \mathrm{mg} / 50 \mathrm{ml}$, initial metal ion concentrations $0.34-7.84 \mathrm{mmol} / \mathrm{L}$ of $\mathrm{Ni}^{2+}, 0.65-5.43 \mathrm{mmol} / \mathrm{L}$ of $\mathrm{Cd}^{2+}$ and $0.43-9.56 \mathrm{mmol} / \mathrm{L}$ of $\mathrm{Pb}^{2+}$ and treatment time $24 \mathrm{~h}$. The kinetic experiments were also performed with same sample at constant metal ion concentrations (for $\mathrm{Ni}^{2+}, \mathrm{Cd}^{2+}$ and $\mathrm{Pb}^{2+}$ at $4.46,5.52$ and $9.56 \mathrm{mmol} / \mathrm{L}$, respectively) for times of $0.5-$ $6 \mathrm{~h}$.

After the removal experiments, the solid samples were filtered, washed several times with deionized water, dried at $50^{\circ} \mathrm{C}$ overnight, and identified by XRD. An atomic absorption spectrophotometer (Shimadzu AA-6800) was used to determine the concentrations of metal ions in the solutions before and after the removal experiments.

\section{Results and discussion}

\subsection{Characterization of starting material and its products}

The chemical compositions obtained by XRF and TG-DTA show that the major components of the CFA are $\mathrm{SiO}_{2}, \mathrm{Al}_{2} \mathrm{O}_{3}$ and unburned carbon (Table 1). The XRD traces (Fig. 1(a)) show that the major crystalline phases are $\alpha$-quartz $\left(\mathrm{SiO}_{2}\right)$ and mullite $\left(3 \mathrm{Al}_{2} \mathrm{O}_{3} \cdot 2 \mathrm{SiO}_{2}\right)$, together with amorphous components. The presence of spherical particles composed of aluminosilicate and big lumps of unburned carbon can be seen in the SEM micrograph (Fig. 1(b)). The specific surface area of as-received CFA was found to have $c a .6 \mathrm{~m}^{2} / \mathrm{g}$.

Table 1: $\quad$ Chemical composition of coal fly ash (CFA).

\begin{tabular}{llllllllll}
\hline Component & $\mathrm{SiO}_{2}$ & $\mathrm{Al}_{2} \mathrm{O}_{3}$ & $\mathrm{CaO}$ & $\mathrm{C}$ & $\mathrm{Fe}_{2} \mathrm{O}_{3}$ & $\mathrm{TiO}_{2}$ & $\mathrm{MgO}$ & $\mathrm{K}_{2} \mathrm{O}$ & Other \\
mass $\%$ & 50.9 & 26.2 & 4.5 & 8.0 & 4.3 & 1.5 & 1.3 & 1.1 & 2.2 \\
\hline
\end{tabular}

In order to determine the optimum conversion conditions and to obtain $\mathrm{Na}-\mathrm{X}$ or Na-A with good crystallinity, several parameters such as $\mathrm{NaOH} / \mathrm{CFA}$ ratio, aging time, $\mathrm{NaOH}$ concentration by adding various amount of water, reaction time and temperature were varied. The fusion temperature was based on the activation temperature in the general preparation of activated carbon [18]. 

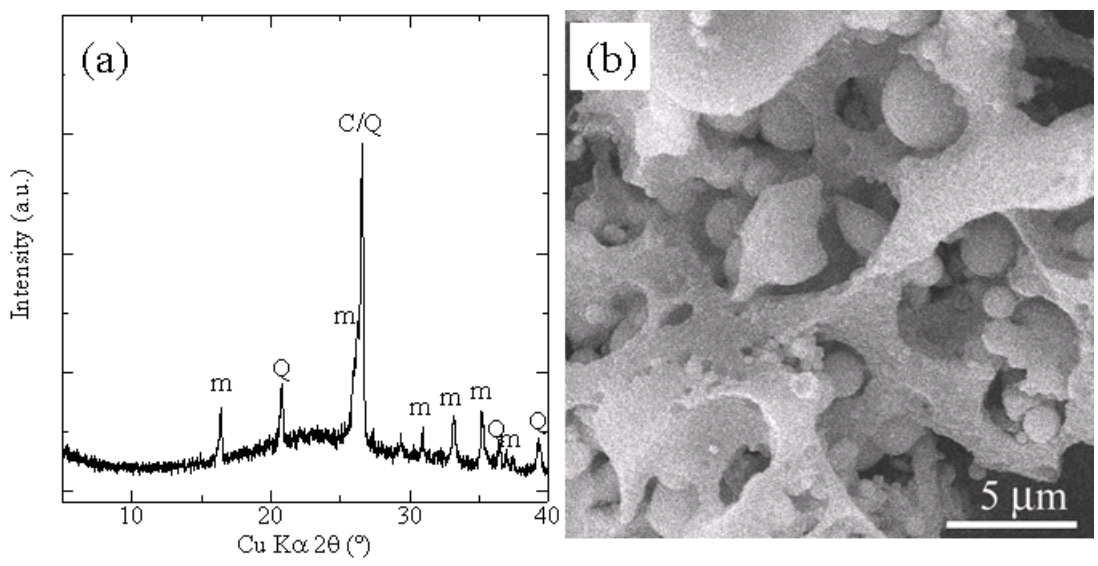

Figure 1: (a) XRD pattern and (b) SEM micrograph of as-received CFA. Symbols: C- unburned carbon, Q- quartz and m- mullite.

The specific surface area and the pore size distribution, evaluated by $\mathrm{N}_{2}$ adsorption isotherm measurement of treated CFA as a function of $\mathrm{NaOH} / \mathrm{CFA}$ ratio, suggested maximum surface area and formation of mesopores at the optimum mass ratio of 2 . In order to find the influence of the aging time, the fused CFA was subjected to the variation of aging time in between 2-24 $\mathrm{h}$ before the hydrothermal treatment. The crystallinity of Na-X was strengthened while that of $\mathrm{Na}-\mathrm{A}$ was weakened with elongation of aging time. Furthermore the crystallinities of both $\mathrm{Na}-\mathrm{X}$ and $\mathrm{Na}-\mathrm{A}$ were strengthened at $2 \mathrm{~h}$ aging times with the variation of the amount of water. Thus, $\mathrm{NaOH} / \mathrm{CFA}$ mass ratio of 2 and the aging time of $2 \mathrm{~h}$ were decided as the optimum conditions before the variations of amounts of water, reaction time and temperature for hydrothermal treatments of treated CFA.

In order to determine the effect of $\mathrm{NaOH}$ concentration on the product, the fused CFA was suspended in various amounts of water $(12-48 \mathrm{ml})$ followed by aging for $2 \mathrm{~h}$, and the suspension was hydrothermally treated at $80^{\circ} \mathrm{C}$ for $24 \mathrm{~h}$. The XRD patterns of the resulting materials with the variation of amounts of water are shown in Fig. 2. At $12 \mathrm{ml}$ water, Na-X with good crystallinity was formed. The peak intensities of $\mathrm{Na}-\mathrm{X}$ were weakened with increasing amount of water, while the peaks of Na-A were strengthened. At $30 \mathrm{ml}$ water, almost single phase Na-A was obtained, whereas with further increasing amount of water to 48 $\mathrm{ml}$, the sample became completely amorphous suggesting the formation of geopolymer. The $\mathrm{Si} / \mathrm{Al}$ molar ratio of $\mathrm{Na}-\mathrm{A}$ is 1 while that in CFA is ca. 2 . This indicates the presence of amorphous $\mathrm{SiO}_{2}$ along with $\mathrm{Na}-\mathrm{A}$.

Next, reaction temperature $\left(60-120^{\circ} \mathrm{C}\right)$ and time $(2-24 \mathrm{~h})$ were examined. Consequently, the crystallinities of $\mathrm{Na}-\mathrm{X}$ and $\mathrm{Na}-\mathrm{A}$ obtained by hydrothermal treatments for $24 \mathrm{~h}$ were promoted with increasing reaction temperature up to $80^{\circ} \mathrm{C}$. They were, however, decomposed and transformed into sodalite above $100^{\circ} \mathrm{C}$. Na-X and Na-A with good crystallinities were produced at $80^{\circ} \mathrm{C}$ within $24 \mathrm{~h}$. Thus, the reaction temperature and time were set at $80^{\circ} \mathrm{C}$ and $24 \mathrm{~h}$, respectively. 


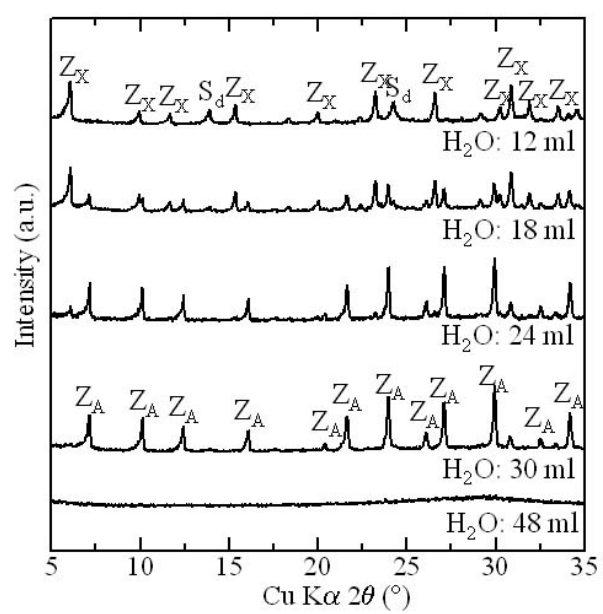

Figure 2: $\quad \mathrm{XRD}$ patterns of products from CFA with variation of amounts of water. Symbol: $\mathrm{Z}_{\mathrm{A}^{-}} \mathrm{Na}-\mathrm{A}, \mathrm{Z}_{\mathrm{X}^{-}} \mathrm{Na}-\mathrm{X}$ and $\mathrm{S}_{\mathrm{d}^{-}}$sodalite.

\subsection{Metal ion sorption isotherms}

The larger size of window cage and higher concentration of $\mathrm{Na}^{+}$of $\mathrm{Na}-\mathrm{X}$ are favorable features for its higher metal ion sorption capacity. Hence the removal characteristics of $\mathrm{Ni}^{2+}, \mathrm{Cd}^{2+}$ and $\mathrm{Pb}^{2+}$ were carried out with $\mathrm{Na}-\mathrm{X}$ material obtained from CFA. The plots of the release of $\mathrm{Na}^{+}$as a function of metal ion sorption show that the removal reactions for these metals progress principally by cation exchange, because the molar ratio of $\mathrm{M}^{2+} / \mathrm{Na}^{+}$is approximately 2 .

The sorption isotherms of $\mathrm{Me}^{2+}(\mathrm{Me}=\mathrm{Ni}, \mathrm{Cd}$ and $\mathrm{Pb})$ were simulated by mathematical equations of Langmuir [19] and Freundlich and Heller [20]. The Langmuir model assumes that the removal of metal ion occurs on a homogenous surface by monolayer sorption, and predicts a linear relation between $\left(\mathrm{C}_{\mathrm{e}} / \mathrm{Q}_{\mathrm{e}}\right)$ and $\mathrm{C}_{\mathrm{e}}$.

$$
\left(\frac{\mathrm{C}_{\mathrm{e}}}{\mathrm{Q}_{\mathrm{e}}}\right)=\left(\frac{1}{\mathrm{Q}_{\max }}\right) \mathrm{C}_{\mathrm{e}}+\left(\frac{1}{\mathrm{Q}_{\max } \cdot \mathrm{b}}\right)
$$

where $C_{\mathrm{e}}(\mathrm{mmol} / \mathrm{L})$ is the equilibrium concentration, $\mathrm{Q}_{\mathrm{e}}(\mathrm{mmol} / \mathrm{g})$ is the amount sorbed at equilibrium, $\mathrm{Q}_{\max }(\mathrm{mmol} / \mathrm{g})$ is the monolayer sorption capacity and $\mathrm{b}$ $(\mathrm{L} / \mathrm{mmol})$ is the Langmuir constant.

On the other hand, the Freundlich model, which is encompassing the surface heterogeneity and exponential distribution of active sites, provides an empirical relationship between the sorption capacity and equilibrium constant of the sorbent. The mathematical representation of this model in linear form is

$$
\log _{\mathrm{e}}=\frac{1}{\mathrm{n}} \log _{\mathrm{e}}+\log _{\mathrm{f}}
$$

where, $\mathrm{K}_{\mathrm{f}}(\mathrm{mmol} / \mathrm{g})$ and $\mathrm{n}(\mathrm{g} / \mathrm{L})$ are the Freundlich constants related to the sorption capacity and sorption affinity of the sorbent, respectively. 
The resulting sorption isotherms are shown in Fig. 3. The parameters calculated from the Langmuir and Freundlich equations using the experimental data are listed in Table 2. The solid and dash line curves in Fig. 3 are calculated from the resulting Langmuir and Freundlich parameters, respectively. The statistical analyses (Table 2) indicated that the Langmuir isotherm could characterize the sorption with a high correlation coefficient values suggesting that the sorption isotherms are of the Langmuir type. The resulting $\mathrm{Q}_{\max }$ values decrease in the order $\mathrm{Pb}^{2+}>\mathrm{Cd}^{2+}>\mathrm{Ni}^{2+}$.

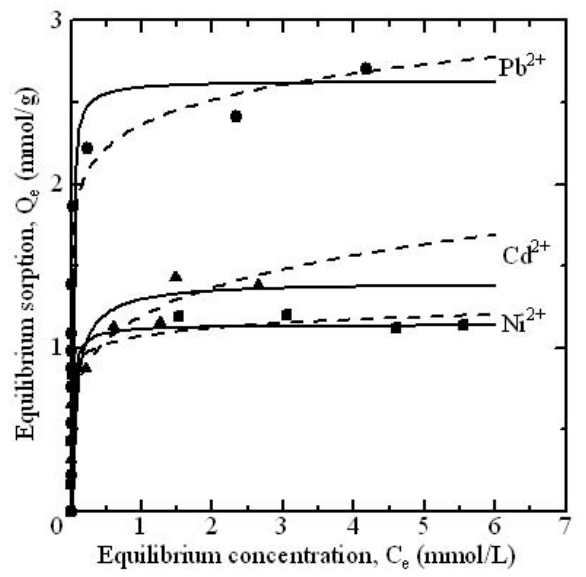

Figure 3: $\quad$ Sorption isotherms of $\mathrm{Ni}^{2+}, \mathrm{Cd}^{2+}$ and $\mathrm{Pb}^{2+}$ by $\mathrm{Na}-\mathrm{X}$ obtained from CFA. Solid and dash lines represent predicted data from Langmuir and Freundlich parameters, respectively.

Table 2: $\quad$ Parameters of isotherms for sorption of $\mathrm{Ni}^{2+}, \mathrm{Cd}^{2+}$ and $\mathrm{Pb}^{2+}$ by Na$\mathrm{X}$ obtained from CFA.

\begin{tabular}{l|cccccc}
\hline $\mathrm{Me}^{2+}$ & \multicolumn{3}{|c}{ Langmuir's parameters } & \multicolumn{3}{c}{ Freundlich's parameters } \\
\cline { 2 - 7 } & $\begin{array}{c}\mathrm{b} \\
(\mathrm{L} / \mathrm{mmol})\end{array}$ & $\begin{array}{c}\mathrm{Q}_{\max } \\
(\mathrm{mmol} / \mathrm{g})\end{array}$ & $\mathrm{R}^{2}$ & $\begin{array}{c}\mathrm{n} \\
(\mathrm{g} / \mathrm{L})\end{array}$ & $\begin{array}{c}\mathrm{K}_{\mathrm{f}} \\
(\mathrm{mmol} / \mathrm{g})\end{array}$ & $\mathrm{R}^{2}$ \\
\hline $\mathrm{Ni}^{2+}$ & 44.5 & 1.14 & 0.9991 & 15.5 & 1.07 & 0.8524 \\
$\mathrm{Cd}^{2+}$ & 12.9 & 1.40 & 0.9881 & 5.2 & 1.20 & 0.8722 \\
$\mathrm{~Pb}^{2+}$ & 67.9 & 2.63 & 0.9971 & 11.2 & 2.63 & 0.8844 \\
\hline
\end{tabular}

This metal ion removal series is in agreement with those previously reported for Na-A [21], Na-P1 [22] and clinoptilolite [23]. The electronic configurations of $\mathrm{Pb}^{2+}$ and $\mathrm{Cd}^{2+}$ are $d^{10}$ and hence have zero-ligand-field stabilization in octahedral aqua complexes. Thus $\mathrm{Pb}^{2+}$ and $\mathrm{Cd}^{2+}$ interact strongly with the zeolite framework during the metal ion removal process in comparison to $\mathrm{Ni}^{2+}$, whose electronic configuration is $d^{8}$ [21]. 


\subsection{Sorption kinetics}

The sorption of metal ions $\left(\mathrm{Ni}^{2+}, \mathrm{Cd}^{2+}\right.$ and $\left.\mathrm{Pb}^{2+}\right)$ by $\mathrm{Na}-\mathrm{X}$ obtained from CFA as a function of contact time is shown in Fig. 4. These plots indicate that the sorption progresses in two steps, initially the rapid sorption within 30 minutes followed by a slower second step during which equilibrium is attained. This behavior of sorption is consistent with previously reported $[24,25]$. The rapid step is due to the abundant availability of active sites on the sorbent material, and as these sites become increasingly occupied, the sorption becomes less efficient and slower.

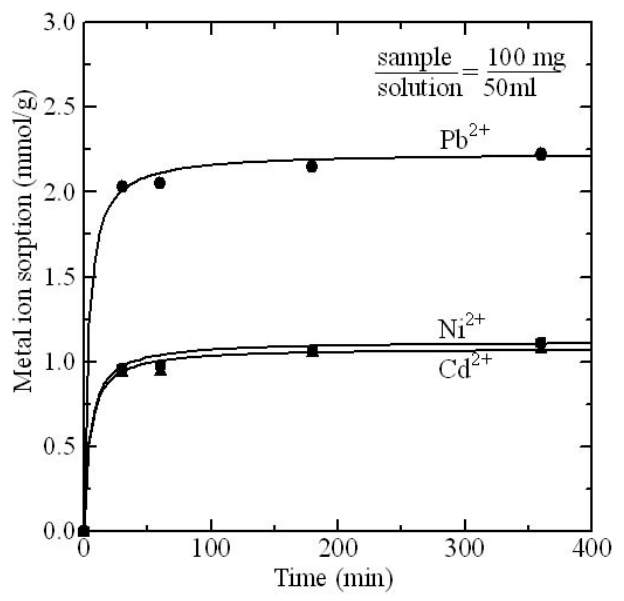

Figure 4: Plots of metal ions sorbed on Na-X prepared from CFA as a function of contact time. Solid lines represent predicted data by a pseudo-second order model.

In order to investigate the rate law describing the metal ion sorption, the kinetic data obtained from the batch experiments were analyzed using two kinetic equations, namely, the first-order equations proposed by Lagergren and Svenska [26] and the pseudo-second order equation proposed by Ho et al. [27]. The equations were rearranged to obtain the linear forms as follows:

$$
\begin{gathered}
\log \left(\mathrm{Q}_{\mathrm{e}}-\mathrm{Q}_{\mathrm{t}}\right)=\log \mathrm{Q}_{\mathrm{e}}-\frac{\mathrm{K}_{1}}{2.303} \mathrm{t} \\
\frac{\mathrm{t}}{\mathrm{Q}_{\mathrm{t}}}=\frac{1}{\left(\mathrm{~K}_{2} \mathrm{Q}_{\mathrm{e}}{ }^{2}\right)}+\frac{1}{\mathrm{Q}_{\mathrm{e}}} \mathrm{t}
\end{gathered}
$$

where $\mathrm{Q}_{\mathrm{t}}$ is the amount adsorbed $(\mathrm{mmol} / \mathrm{g})$ at time $\mathrm{t}(\mathrm{min}), \mathrm{C}_{\mathrm{e}}$ and $\mathrm{Q}_{\mathrm{e}}$ are as in equation (1), $K_{1}$ and $K_{2}$ are rate constants of equations (3) and (4), respectively. Equations (3) and (4) yielded the rate constants $\left(\mathrm{K}_{1}\right.$ and $\left.\mathrm{K}_{2}\right)$ and the equilibrium metal ion sorption $\mathrm{Q}_{\mathrm{e}}$, presented in Table 3. The $\mathrm{Q}_{\mathrm{e}}$ values obtained from the pseudo-second order equation (4) are comparable with the $\mathrm{Q}_{\max }$ values obtained from the Langmuir equation (1) (Table 2), indicating the pseudo-second order reaction model is more appropriate for metal ion sorption. 
Table 3: $\quad$ Kinetic data for $\mathrm{Na}-\mathrm{X}$ estimated from various equations.

\begin{tabular}{c|cccc}
\hline System & $\begin{array}{c}\mathrm{K}_{1} \text { from } \\
\text { equation (3) }\end{array}$ & $\begin{array}{c}\mathrm{K}_{2} \text { from } \\
\text { equation (4) }\end{array}$ & \multicolumn{2}{c}{$\mathrm{Q}_{\mathrm{e}}$ (mmol/g) from } \\
equation (3) & equation (4) \\
\hline $\mathrm{Ni}^{2+}$ & $4.6 \times 10^{-3}$ & 0.20 & 1.97 & 1.12 \\
$\mathrm{Cd}^{2+}$ & $1.0 \times 10^{-3}$ & 0.21 & 3.35 & 1.08 \\
$\mathrm{~Pb}^{2+}$ & $1.2 \times 10^{-3}$ & 0.14 & 1.23 & 2.23 \\
\hline
\end{tabular}

\section{Conclusion}

Na-X and Na-A zeolites were successfully obtained from CFA. The appropriate conditions for $\mathrm{Na}-\mathrm{X}$ were found to be as: $\mathrm{NaOH}$ fusion temperature $750^{\circ} \mathrm{C}$, amount of water $12 \mathrm{ml}$, reaction temperature $80^{\circ} \mathrm{C}$, longer aging time and reaction time $24 \mathrm{~h}$ while those for $\mathrm{Na}-\mathrm{A}$ are similar to those of $\mathrm{Na}-\mathrm{X}$ except the amount of water in between $24-30 \mathrm{ml}$ and shorter aging time.

Thus obtained composite materials have good sorption characteristics for heavy metals, with sorption isotherm more favorable to Langmuir model. The equilibrium sorption capacity follows the order $\mathrm{Pb}^{2+}>\mathrm{Cd}^{2+}>\mathrm{Ni}^{2+}$. The high removal of $\mathrm{Pb}^{2+}$ and $\mathrm{Cd}^{2+}$ was expected to be due to the ligand-field stabilization. The overall sorption process was pseudo-second order with an initial rapid and quantitatively predominant sorption followed by a second slower and quantitatively insignificant sorption.

\section{Acknowledgements}

This work was supported by a Grant-in-Aid from Okayama Prefectural Government and Okayama Prefecture Industrial Promotion Foundation, and in part by a Grant-in-Aid from the Okayama University 21st Century COE program "Strategic Solid Waste Management for Sustainable Society".

\section{References}

[1] Baltrus, J.P., Wells, A.W., Fauth, D.J., Diehl, J.R. and White, C.M., Characterization of Carbon Concentrates from Coal-Combustion Fly Ash, Energy \& Fuels, 15, pp. 455-462, 2001.

[2] Jha, V.K., Matsuda, M., Miyake, M., Resource recovery from coal fly ash waste: an overview study, Journal of the Ceramic Society of Japan, 116, 2008.

[3] Dirk, G., Pulverised fuel ash products solve the sewage sludge problems of the wastewater industry, Waste Management, 16, 51-57 (1996).

[4] Andres, A., Ortiz, I., Viguri, J.R. and Irabien, A., Long-term behaviour of toxic metals in stabilized steel foundry dusts, Journal of Hazardous Materials, 40, pp. 31-42, 1995. 
[5] Pickles, C.A., McLean, A., Alcock, C.B. and Nikolic, R.N., Plasma recovery of metal values from fly ash, Canadian Metallurgical Quarterly, 29, pp. 193-200, 1990.

[6] Font, O., Querol, X., Plana, F., López-Soler, A., Chimenos, J.M., March, M.J., Espiell, F., Burgos, S., García, F. and Alliman, C., Occurrence and distribution of valuable metals in fly ash from Puertollano IGCC power plant, Spain, International Ash Utilization Symposium, 22-24 October, Hyatt Regency Lexington, Lexington, KY, USA, 2001.

[7] Garea, A., Viguri, J.R. and Irabien, A., Kinetics of flue gas desulphurization at low temperatures: fly ash/calcium (3/1) sorbent behavior, Chemical Engineering Science, 52, pp. 715-732, 1997.

[8] Vilches, L.F., Fernández-Pereira, C., Olivares, J., Rodriguez Piñeiro, M. and Vale, J., Development of new fire-proof products made from coal fly ash, PROGRES Workshop on Novel Products from Combustion Residues, Morella, Spain, pp. 343-351, 2001.

[9] Kruger, R.A., Fly ash beneficiation in South Africa: creating new opportunities in the market-place, Fuel, 76, pp. 777-779, 1997.

[10] Anderson, M. and Jackson, G., The beneficiation of power station coal ash and its use in heavy clayware ceramics, British Ceramic Transactions and Journal, 82, pp. 34-42, 1983.

[11] Stoch, L., Kordek M. and Nadachowski, F., Processing of some nonconventional ceramic raw materials and by-products, Ceramics International, 12, pp. 213-220, 1986.

[12] Queralt, I., Querol, X., López-Soler, A. and Plana, F., Use of coal fly ash for ceramics: a case study for a large Spanish power station, Fuel, 76, pp.787-791, 1997.

[13] Querol, X., Moreno, N., Umaña, J.C., Alastuey, A., Hernández, E., LópezSoler, A. and Plana, F., Synthesis of zeolites from coal fly ash: an overview, International Journal of Coal Geology, 50, pp. 413-423, 2002.

[14] Miyake, M., Kimura, Y., Ohashi, T., and Matsuda, M., Preparation of activated carbon-zeolite composite materials from coal fly ash, Microporous and Mesoporous Materials, In press.

[15] Shigemoto, N., Hayashi, H., and Miyaura, K., Selective formation of Na-X, zeolite from coal fly ash by fusion with sodium hydroxide prior to hydrothermal reaction, Journal of Materials Science, 28, pp. 4781-4786, 1993.

[16] Hollman, G.G., Steenbruggen, G. and Janssen-Jurkovièová, M., A two-step process for the synthesis of zeolites from coal fly ash, Fuel, 78, pp. 12251230, 1999.

[17] Park, M., Choi, C.L., Lim, W.M., Kim, M.C., Choi, J. and Heo, N.H., Molten-salt method for the synthesis of zeolitic materials. I. Zeolite formation in alkaline molten-salt system, Microporous and Mesoporous Materials, 37, pp. 81-89, 2000.

[18] Sanada, Y., Suzuki, M., and Fujimoto, K. (Eds), Shinpan-Kasseitan (in Japanese). Kodansha Scientific Co., Tokyo, pp.51-54, 1992. 
[19] Langmuir, I.J., The adsorption of gases on plane surfaces of glass, mica and platinum, Journal of the American Chemical Society, 40, pp.1361-1403, 1918.

[20] Freundlich, H. and Heller, W., The adsorption of cis- and transazobenzene, Journal of the American Chemical Society, 61, pp. 2228-2230, 1939.

[21] Majdan, M., Pikus, S., Kowalska-Ternes, M., Gładysz-Płaska, A., Staszczuk, P., Fuks, L. and Skrzypek, H., Equilibrium study of selected divalent d-electron metals adsorption on A-type zeolite, Journal of Colloid and Interface Science, 262, pp. 321-330, 2003.

[22] Steenbruggen, G. and Hollman, G.G., The synthesis of zeolites from fly ash and the properties of the zeolite products, Journal of Geochemical Exploration, 62, pp. 305-309, 1998.

[23] Ouki, S.K. and Kavanagh, M., Performance of natural zeolites for the treatment of mixed metal-contaminated effluents, Waste Management and Research, 15, pp. 383-394, 1997.

[24] Sag, Y. and Kutsal, T., The selective biosorption of chromium(VI) and copper(II) ions from binary metal mixtures by $R$. arrhizus, Process Biochemistry, 31, pp. 561-572, 1996.

[25] Nouri, L., Ghodbane, I., Hamdaoui, O. and Chiha, M., Batch sorption dynamics and equilibrium for the removal of cadmium ions from aqueous phase using wheat bran, Journal of Hazardous Materials, 149, pp. 115-125, 2007.

[26] Lagergren, S. and Svenska, B.R., Zur theorie der sogenannten adsorption geloester stoffe, Veternskapsakad Handlinger, 24, pp. 1-39, 1898.

[27] Ho, Y.S., Chiu, W.T., Hsu, C.S. and Huang, C.T., Sorption of lead ions from aqueous solution using tree fern as a sorbent, Hydrometallurgy, 73, pp. 55-61, 2004. 